OPEN ACCESS

Edited by:

Zsolt Illes,

University of Southern Denmark

Odense, Denmark

Reviewed by:

Maria José Sá,

Centro Hospitalar São João,

Portugal

Moussa Antoine Chalah, Hôpitaux Universitaires

Henri Mondor, France

Ralf Lürding,

University of Regensburg,

Germany

*Correspondence: Jack Cotter

jack.cotter@camcog.com

tJoint final authors.

Specialty section:

This article was submitted to

Multiple Sclerosis and

Neuroimmunology,

a section of the journal

Frontiers in Neurology

Received: 22 February 2018 Accepted: 25 April 2018

Published: 11 May 2018

Citation:

Cotter J, Vithanage N, Colville S, Lyle D, Cranley D, Cormack F,

Barnett $\mathrm{JH}$, Murray $\mathrm{K}$ and $\mathrm{Pal} S$

(2018) Investigating Domain-Specific

Cognitive Impairment Among

Patients With Multiple Sclerosis

Using Touchscreen Cognitive

Testing in Routine Clinical Care.

Front. Neurol. 9:331.

doi: 10.3389/fneur.2018.00331

\section{Investigating Domain-Specific Cognitive Impairment Among Patients With Multiple Sclerosis Using Touchscreen Cognitive Testing in Routine Clinical Care}

\author{
Jack Cotter ${ }^{*}$, Nethmi Vithanage ${ }^{2}$, Shuna Colville ${ }^{3}$, Dawn Lyle $^{3}$, Denise Cranley ${ }^{3}$, \\ Francesca Cormack ${ }^{1}$, Jennifer H. Barnett ${ }^{1,4}$, Katy Murray ${ }^{3,5,6+}$ and Suvankar Pal ${ }^{3,5,6+}$
}

\begin{abstract}
${ }^{1}$ Cambridge Cognition, Cambridge, United Kingdom, ${ }^{2}$ College of Medicine and Veterinary Medicine, University of Edinburgh, Edinburgh, United Kingdom, ${ }^{3}$ Anne Rowling Regenerative Neurology Clinic, University of Edinburgh, Edinburgh, United Kingdom, ${ }^{4}$ Department of Psychiatry, University of Cambridge, Cambridge, United Kingdom, ${ }^{5}$ Forth Valley Royal Hospital, Larbert, United Kingdom, ${ }^{6}$ Centre for Clinical Brain Sciences, University of Edinburgh, Edinburgh, United Kingdom
\end{abstract}

Cognitive dysfunction is present in up to $70 \%$ of patients with multiple sclerosis (MS) and has been reported at all stages and in all subtypes of the disease. These deficits have been reported across a variety of cognitive domains, but are generally under-recognized and incompletely evaluated in routine clinical practice. The aim of this study was to investigate the spectrum of cognitive impairment in patients with MS presenting to a specialist MS clinic using the Cambridge Neuropsychological Test Automated Battery (CANTAB), administered on a touchscreen platform. Ninety MS patients completed computerized CANTAB tasks assessing working memory, executive function, processing speed, attention, and episodic memory. Scores were adjusted for age, sex, and level of education and classified as normal or impaired based on comparison with a large normative data pool. We also investigated the impact of clinical and demographic variables which could potentially influence cognitive performance including patient educational level (a proxy for cognitive reserve), disease status (duration, course, and severity of MS), and depression. CANTAB testing detected cognitive impairment in 40 patients (44\% of the sample). The most frequently impaired domain was executive function, present in $55 \%$ of cognitively impaired individuals. Disease duration and severity were significantly associated with performance across various cognitive domains. Patients with depressive symptoms were also more likely to exhibit impaired processing speed. Results from this study confirm that cognitive impairment is common and occurs across a range of domains among MS patients attending routine clinical visits. CANTAB tasks provide a sensitive and practical approach to cognitive testing in MS patients as part of a holistic patient assessment.

Keywords: multiple sclerosis, cognition, Cambridge Neuropsychological Test Automated Battery, computerized testing, neuropsychological assessment 


\section{INTRODUCTION}

Cognitive dysfunction is present in up to $70 \%$ of patients with multiple sclerosis (MS) and has been reported at all stages and in all subtypes of the disease (1-3). These deficits have been reported across a variety of cognitive domains and are thought to arise as a result of the diffuse white and gray matter damage associated with MS (4-6). Cognitive dysfunction is a leading cause of disability in MS and is associated with unemployment $(7,8)$, increased caregiver burden $(9,10)$, and poor quality of life (11-13). However, cognitive impairment is often under-recognized and incompletely evaluated in patients with MS (6).

Cognitive deterioration is often overlooked, in part, due to a lack of tools suitable for use in routine clinical practice. Cognitive batteries are typically time-consuming, require specialist resources and a trained rater to administer and interpret the results of these tests. While a number of cognitive batteries have been developed specifically for use in patients with MS, including the Brief Repeatable Battery of Neuropsychological tests (BRBN) (14), the Minimal Assessment of Cognitive Function in MS (15), and the Brief International Cognitive Assessment for MS (BICAMS) (16), these retain many of these practical limitations. There is a need for sensitive as well as time and resource-efficient tests for detecting cognitive impairment as part of routine holistic patient assessment in MS clinics.

The Cambridge Neuropsychological Test Automated Battery (CANTAB) consists of a number of computerized tests that can be administered via touchscreen platforms to assess discrete cognitive subdomains $(17,18)$. These have been developed and validated over the past 30 years and offer potential benefits over conventional paper-and-pencil based cognitive tests (19). These touchscreen tasks ensure accurate response scoring and provide precise assessment of reaction-time based measures. Automated instructions are available in a range of languages and tasks can be largely self-administered by patients, requiring no technical knowledge or prior familiarity. Automatic scoring and comparison to normative data also provides clinicians with an indication of a patient's level of cognitive performance relative to individuals of a similar age, sex, and level of education in the general population. CANTAB tasks have demonstrated sensitivity to cognitive dysfunction and have been widely used across a range of clinical groups (20-23), including patients with MS (24-26). The aim of this study was to investigate domain-specific cognitive impairment in patients with MS using CANTAB in routine clinical care. We also sought to examine whether patient educational level [a proxy for cognitive reserve (27)], disease status (duration, course, and severity of MS), or depression were associated with cognitive performance.

\section{MATERIALS AND METHODS}

\section{Patients}

105 consecutive patients attending a specialist MS clinic at the Anne Rowling Regenerative Neurology Clinic, University of Edinburgh, between March 2014 and October 2014 were offered the opportunity to complete a series of cognitive tests as part of their routine holistic clinical assessment. All patients included in the current study met McDonald criteria for MS (28). None of the patients were in acute relapse at the time of the assessment. Electronic patient records, clinical case notes, and patient interviews were reviewed to determine patient demographics, disease course, duration, and Expanded Disability Status Scale (EDSS) (29) score (reflecting the degree of physical disability). Patients were also screened for depression using a touchscreen version of the 15-item Geriatric Depression Scale (GDS) (30).

\section{Cognitive Testing}

Three automated CANTAB neuropsychological tests were administered using a touchscreen tablet computer (iPad Air, Apple Inc.). The user-friendly touchscreen platform used for patient testing required no prior neuropsychological training for administration. Each task incorporated an automated computer voiceover providing instructions to patients. The cognitive assessment battery took approximately 15 minutes to complete:

1. Match to Sample: assesses processing speed and attention

2. Paired Associates Learning: assesses visuospatial episodic memory

3. Spatial Working Memory: assesses working memory and executive function (specifically strategic planning)

Upon completion of cognitive testing, patient raw scores for each cognitive domain were internally processed by the software to create $z$-scores. These $z$-scores were standardized for age, sex, and education status using data from an inbuilt normative database collected from healthy adults aged 18-90 years. Based on these $z$-scores, cognitive performance levels were categorized from "superior" $(z$-score $>1.5)$ to "very poor" $(z$-score $<-2)$, though "average" $(z$-score $\geq-1)$ was the highest possible category for some tests. Patients scoring "poor" or "very poor" $(z$-score $<-1.5)$ in a cognitive domain were considered to be impaired relative to their age, sex, and education-matched peers.

\section{Statistical Analyses}

Data were analyzed using SPSS statistical software (IBM SPSS Statistics for Windows, Version 23.0. Armonk, NY, USA: IBM Corp.). Chi-square test and Fisher's exact test were used to examine group differences in the proportion of patients demonstrating cognitive impairment in each cognitive domain based on level of education, depression, and MS disease course. Spearman's rankorder correlation test was used to examine associations between disease duration and severity with cognitive performance, based on the aforementioned $z$-score derived performance categories. All analyses were two-tailed, $p<0.05$ was considered statistically significant.

\section{Ethical Approval}

As cognitive assessments were performed as part of routine clinical evaluation of patients, and clinical data were handled in an anonymized fashion, the Local Research Ethics Committee deemed that specific ethical approval was not required for this study. 


\section{RESULTS}

\section{Patient Characteristics}

Ninety MS patients completed the CANTAB assessments (mean age $44.5 \pm 10.9$ years, range: $22-70$ years). The average duration of disease was $11.4 \pm 9.0$ years (range: $0-39$ years). The average EDSS score was $3.6 \pm 2.4$ (range: $0-7.5$ ). Further demographic and clinical characteristics of the patients included in this study are presented in Table $\mathbf{1}$. Fifteen patients were excluded (Figure 1), though further details on the MS patients that did not complete the CANTAB assessments $(n=9)$ were not recorded.

\section{Cognitive Impairment in MS}

CANTAB tests detected cognitive impairment in at least one cognitive domain among 40 (44\%) of the patients. Twenty-three percent of cases demonstrated impairment across multiple cognitive domains (Figure 2). Executive function was the most commonly impaired domain (Figure 3A) and was present in $55 \%$ of patients who exhibited impairment in at least one cognitive domain (Figure 3B).

\section{Association With Education}

For the purposes of the normative comparisons, the education level of patients was recorded into one of three categories; (1) those who left school before the age of 16, (2) those who left

TABLE 1 | Patient clinical and demographic characteristics.

\begin{tabular}{llr}
\hline & & $\boldsymbol{n}(\mathbf{\%})$ \\
\hline Sex & Male & $22(24 \%)$ \\
\multirow{3}{*}{ Level of education } & Female & $68(76 \%)$ \\
& Left before age 16 & $9(10 \%)$ \\
& Left age 16-18 & $41(46 \%)$ \\
Multiple sclerosis disease & Left after age 18 & $40(44 \%)$ \\
course & Relapsing-remitting & $65(72 \%)$ \\
& Primary progressive & $10(11 \%)$ \\
& Secondary progressive & $15(17 \%)$
\end{tabular}

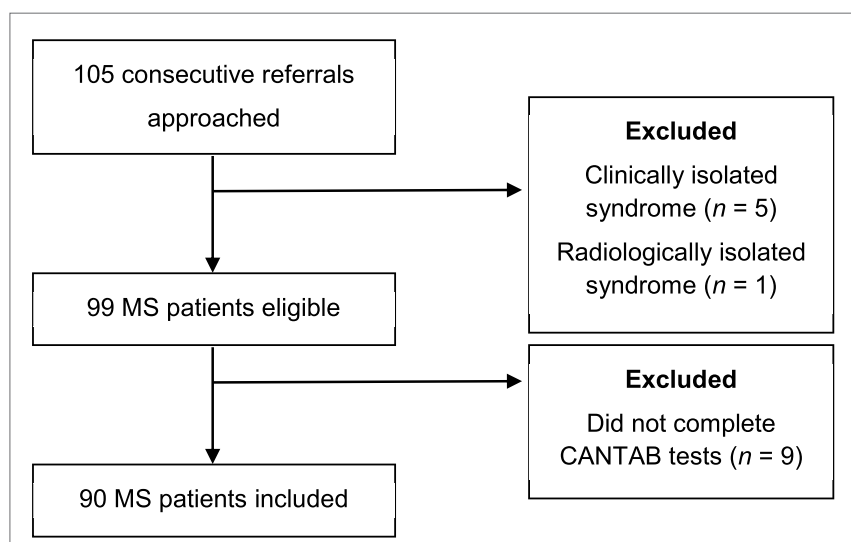

FIGURE 1 | Patient recruitment flowchart. between ages 16 and 18, and (3) those who completed education after 18 years of age. As there were only a small number of individuals who had only completed up to 16 years of education $(n=9)$, we merged categories one and two for the purposes of examining whether cognitive impairment was associated with level of education across the sample. This was intended to serve as a proxy for cognitive reserve, given that higher levels of education are thought to be protective against cognitive decline in MS. We therefore conducted our analyses based on those individuals with $\leq 18(n=50)$ or $>18$ years of education $(n=40)$. There were no significant differences in the proportion of patients with cognitive impairment in any cognitive domain between these two groups (all $p \geq 0.22$ ).

\section{Association With MS Disease Duration, Severity, and Course}

Spearman's rank-order correlations were performed to examine the associations between disease duration and severity with cognitive performance (Table 2). A longer disease duration was associated with poorer performance on measures of processing speed and attention. More severe physical disability (as assessed using the EDSS) was significantly associated with poorer performance on measures of working memory, executive function, processing speed, and attention. A higher proportion of patients with primary progressive $(20 \%)$ and secondary progressive MS (13\%) exhibited impaired attention compared to those with relapsing-remitting MS (3\%), though this did not reach statistical significance $(p=0.056)$. There were no other statistically significant differences in the proportion of patients with impairment in any of the cognitive domains between the different MS disease courses (all $p \geq 0.38$ ).

\section{Association With Depression}

Clinically significant depressive symptoms (GDS $\geq 5$ ) were identified in 33 (37\%) patients. One patient did not complete the GDS questionnaire and was, therefore, excluded from this analysis. When analyzed using Fisher's exact test, a higher proportion of patients with depression exhibited impaired processing speed compared to non-depressed patients $(p=0.013)$. There were no significant differences in the proportion of cognitively impaired individuals between the depressed and non-depressed patients in any other domains (all $p \geq 0.061$ ).

\section{DISCUSSION}

\section{Summary of Results}

Cognitive impairment was identified using CANTAB in $44 \%$ of patients attending routine appointments at a specialist MS clinic. This figure is comparable to the proportion of MS patients affected by cognitive impairment reported in other studies based on longer and more resource-intensive cognitive batteries (31-33). Executive function (specifically strategic planning) was the domain most commonly impaired among patients. There was also evidence that both disease duration and degree of physical disability may be associated with the severity of cognitive 


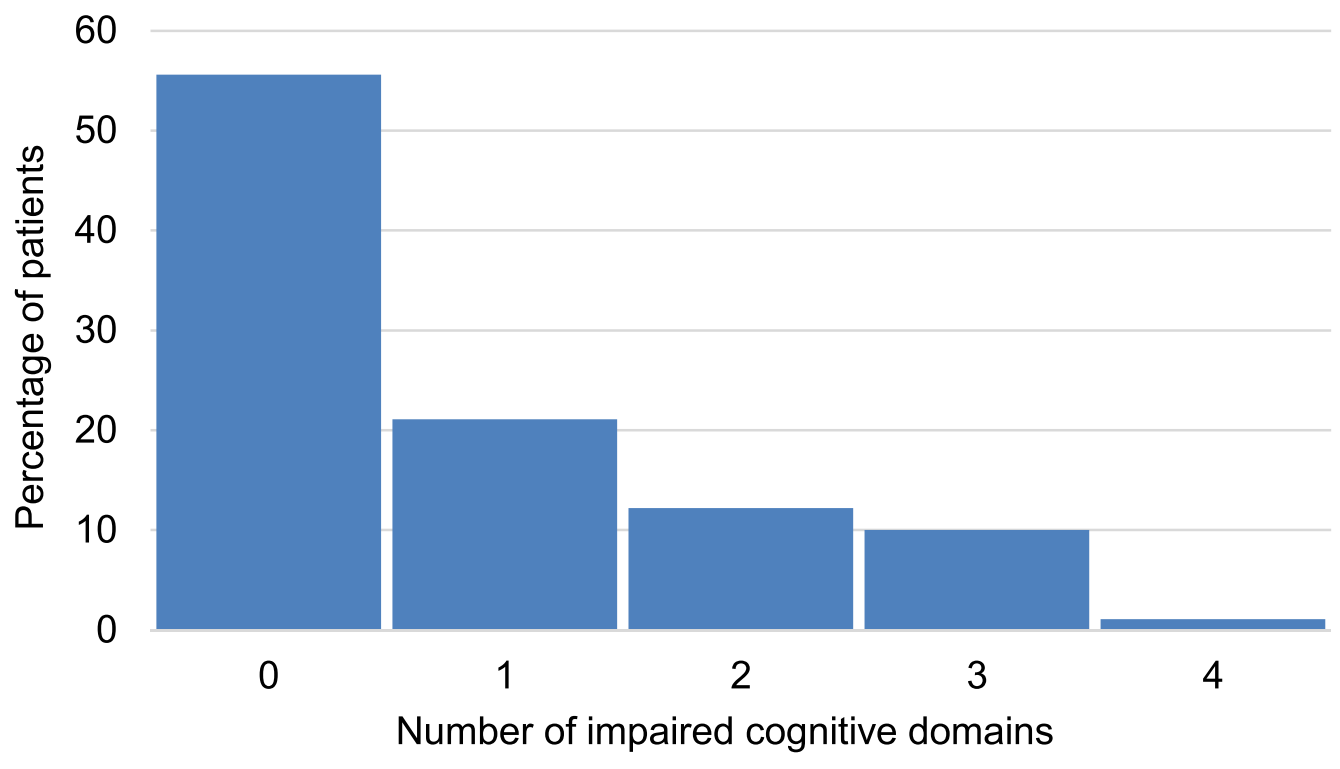

FIGURE 2 | Percentage of multiple sclerosis patients with impairment in different cognitive domains.
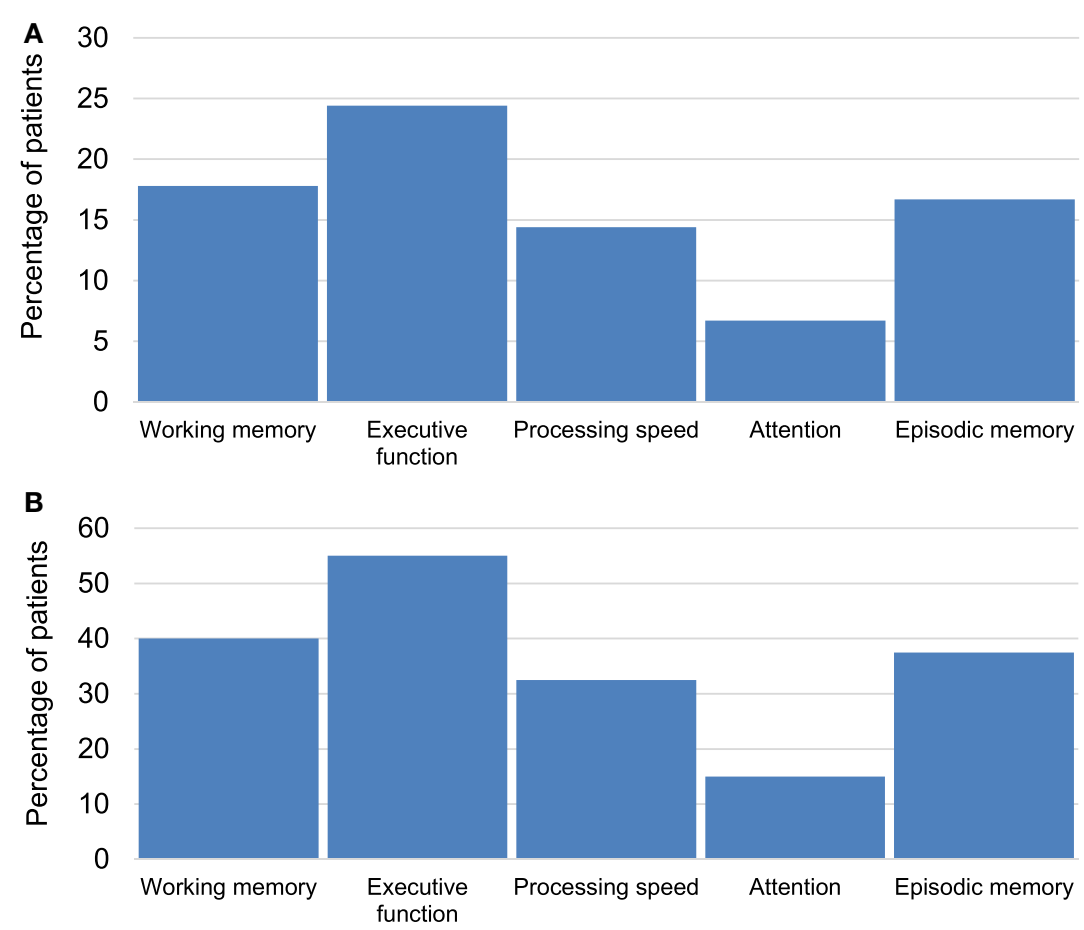

FIGURE 3 | (A) Percentage of multiple sclerosis (MS) patients with impairment in specific cognitive domains across the whole sample $(n=90)$. (B) Percentage of MS patients with impairment in specific cognitive domains among the impaired group $(n=40)$.

dysfunction observed in patients with MS. These results demonstrate that CANTAB tasks can be used to provide a brief yet sensitive and comprehensive assessment of cognition in patients with MS as part of their routine clinical care.

\section{Relationship to Clinical and Demographic Variables}

Consistent with previous research (34), longer disease duration was associated with poorer processing speed and attention. 
TABLE 2 | Correlations between disease duration, severity, and cognitive performance.

\begin{tabular}{|c|c|c|c|c|}
\hline & \multicolumn{2}{|c|}{ Disease duration (years) } & \multicolumn{2}{|c|}{$\begin{array}{c}\text { Disease severity } \\
\text { (Expanded Disability } \\
\text { Status Scale score) }\end{array}$} \\
\hline & $r_{\mathrm{s}}$ & $p$-Value & $r_{\mathrm{s}}$ & $p$-Value \\
\hline Working memory & -0.118 & 0.269 & -0.215 & 0.042 \\
\hline Executive function & -0.083 & 0.436 & -0.224 & 0.034 \\
\hline Processing speed & -0.218 & 0.039 & -0.298 & 0.004 \\
\hline Attention & -0.206 & 0.051 & -0.263 & 0.012 \\
\hline Episodic memory & -0.073 & 0.492 & -0.132 & 0.216 \\
\hline
\end{tabular}

Higher EDSS scores were significantly associated with poorer working memory, executive function, processing speed, and attention. The EDSS is rated by a neurologist and is heavily reliant on walking as the main factor for quantifying disability (29). However, this measure has consistently been reported to be among the strongest correlates of cognitive impairment in MS (35), suggesting similar processes may drive both physical and cognitive disability in patients. We did not identify any statistically significant differences between the different MS disease subtypes in the proportion of patients with impairment across any of the cognitive domains. This is likely due to a lack of power to detect group differences in cognitive performance due to the relatively small number of patients with progressive forms of illness. Larger studies have reported that those MS patients with a progressive disease course exhibit more severe and widespread deficits in cognitive performance compared to those with a relapsing-remitting course $(36,37)$. This is perhaps unsurprising given that relapsing-remitting MS is characterized by bouts of inflammation and periods of recovery and remyelination whereas in the progressive phase, episodes of inflammation and demyelination become more infrequent with a shift toward neurodegeneration and sustained damage (38).

Cognitive reserve has been identified as a potential buffer against cognitive impairment with intellectually enriching experiences, such as high levels of education, thought to protect against MS-related cognitive decline $(27,39)$. We failed to identify any significant differences in the proportion of MS patients with cognitive impairment between those who left education prior to age 18 compared to those who went on to further education, though this may be attributable to a lack of variability in the data based on these categories. High GDS scores (indicative of depression) were associated with impaired processing speed, though it is difficult to determine the direction of causality in this cross-sectional association. Patients with major depressive disorder display impaired cognitive performance on CANTAB tests (23); however, cognitive dysfunction has also been shown to adversely affect social and occupational functioning and quality of life in patients with MS $(7,11,12)$, which is also likely to drive depressive symptoms.

\section{Clinical Implications}

Multiple sclerosis is a disease characterized by considerable patient heterogeneity in clinical presentation, lesion profile, and degree of cognitive dysfunction $(4,40,41)$. Cognitive assessment should therefore be an important part of routine clinical care for examining the impact and progression of MS. Detection of cognitive impairment in MS is important, as it allows appropriate support to be instituted, and practical measures to overcome functional deficits to be implemented. Deficits are most commonly reported in processing speed, episodic memory, attention, and executive function among patients with MS, while other domains such as language abilities typically remain intact $(4,6)$. The results of this study indicate that CANTAB tasks are sensitive to impairment in each of these domains most frequently affected in MS. Though there are currently no regulatory approved pharmacological treatments for the amelioration of cognitive dysfunction in MS $(42,43)$, there is emerging evidence that cognitive rehabilitation interventions and physical exercise may exert pro-cognitive effects in this population and may be useful in limiting further cognitive decline (44-48).

\section{Strengths and Limitations}

Cognition was assessed using a brief, computerized cognitive test battery that has been developed and validated by over 30 years of research (17-19), and which has previously been shown to be sensitive to cognitive deficits in patients with MS (24-26). Computerized cognitive testing helps to overcome many of the practical limitations of existing paper-and-pencil- based cognitive tasks in routine clinical care and has been shown to be welltolerated by patients, even among very elderly individuals (49). Though the CANTAB battery used in this project was designed to assess the cognitive domains most frequently impaired in MS, there is an emerging literature suggesting that other cognitive processes, such as social cognition $(5,50)$, may also be adversely affected in this population. However, the "real world" impact of deficits in these abilities remain poorly understood and warrant further investigation prior to inclusion into routine cognitive assessment in clinical care (51).

Nine patients did not complete the CANTAB tests; however, no further clinical or demographic information was recorded for these individuals. It is therefore unclear whether they are missing at random or whether this introduces some bias into the current analyses. Data on the use of disease modifying therapies were also not collected at the time of the assessments, though there is currently limited evidence that these drugs have an impact on cognition (43). An additional limitation of the current study is that information relating to fatigue and daytime sleepiness was not recorded. These are common symptoms among patients with MS and may be associated with poor cognitive performance $(4,52)$. Depressive symptoms were assessed using the GDS, though originally developed for use in older adults, the content is generic and not age-specific (30). Published studies in both clinical and non-clinical populations have demonstrated that this is a sensitive and reliable tool for assessing depressive symptoms in adults of all ages (53-55).

\section{Conclusion}

Results from this study confirm that cognitive impairment is common among patients with MS, that it occurs across a range of domains, and is associated with disease-related variables. CANTAB tasks provide a sensitive and practical tool for cognitive testing in MS patients as part of a holistic patient assessment. 
These computerized touch screen tests help to overcome many of the challenges faced when assessing cognition in clinical practice.

\section{ETHICS STATEMENT}

As cognitive assessments were performed as part of routine clinical evaluation of patients, and clinical data was handled in an anonymized fashion, the Local Research Ethics Committee deemed that specific ethical approval was not required for this study.

\section{AUTHOR CONTRIBUTIONS}

SP, KM, and NV were responsible for the design of the study. FC and JB recommended suitable cognitive tests and interpreted the

\section{REFERENCES}

1. Langdon DW. Cognition in multiple sclerosis. Curr Opin Neurol (2011) 24:244-9. doi:10.1097/WCO.0b013e328346a43b

2. Prakash RS, Snook EM, Lewis JM, Motl RW, Kramer AF. Cognitive impairments in relapsing-remitting multiple sclerosis: a meta-analysis. Mult Scler (2008) 14:1250-61. doi:10.1177/1352458508095004

3. Ruet A, Deloire M, Charré-Morin J, Hamel D, Brochet B. Cognitive impairment differs between primary progressive and relapsing-remitting MS. Neurology (2013) 80:1501-8. doi:10.1212/WNL.0b013e31828cf82f

4. Chiaravalloti ND, DeLuca J. Cognitive impairment in multiple sclerosis. Lancet Neurol (2008) 7:1139-51. doi:10.1016/S1474-4422(08)70259-X

5. Cotter J, Firth J, Enzinger C, Kontopantelis E, Yung AR, Elliott R, et al. Social cognition in multiple sclerosis: a systematic review and meta-analysis. Neurology (2016) 87:1727-36. doi:10.1212/WNL.0000000000003236

6. Rocca MA, Amato MP, De Stefano N, Enzinger C, Geurts JJ, Penner IK, et al. Clinical and imaging assessment of cognitive dysfunction in multiple sclerosis. Lancet Neurol (2015) 14:302-17. doi:10.1016/S1474-4422(14)70250-9

7. Honarmand K, Akbar N, Kou N, Feinstein A. Predicting employment status in multiple sclerosis patients: the utility of the MS functional composite. J Neurol (2011) 258:244-9. doi:10.1007/s00415-010-5736-8

8. Strober LB, Christodoulou C, BenedictRH, Westervelt HJ, Melville P, ScherlWF, et al. Unemployment in multiple sclerosis: the contribution of personality and disease. Mult Scler (2012) 18:647-53. doi:10.1177/1352458511426735

9. Figved N, Myhr KM, Larsen JP, Aarsland D. Caregiver burden in multiple sclerosis: the impact of neuropsychiatric symptoms. J Neurol Neurosurg Psychiatry (2007) 78:1097-102. doi:10.1136/jnnp.2006.104216

10. Labiano-Fontcuberta A, Mitchell AJ, Moreno-García S, Benito-León J. Cognitive impairment in patients with multiple sclerosis predicts worse caregiver's health-related quality of life. Mult Scler (2014) 20:1769-79. doi:10.1177/1352458514532398

11. Phillips LH, Henry JD, Scott C, Summers F, Whyte M, Cook M. Specific impairments of emotion perception in multiple sclerosis. Neuropsychology (2011) 25:131-6. doi:10.1037/a0020752

12. Rao SM, Leo GJ, Ellington L, Nauertz T, Bernardin L, Unverzagt F. Cognitive dysfunction in multiple sclerosis. II. Impact on employment and social functioning. Neurology (1991) 41:692-6. doi:10.1212/WNL.41.5.692

13. Ruet A, Deloire M, Hamel D, Ouallet JC, Petry K, Brochet B. Cognitive impairment, health-related quality of life and vocational status at early stages of multiple sclerosis: a 7-year longitudinal study. J Neurol (2013) 260:776-84. doi:10.1007/s00415-012-6705-1

14. Rao SM. A Manual for the Brief, Repeatable Battery of Neuropsychological Tests in Multiple Sclerosis. Milwaukee: Medical College of Wisconsin (1990).

15. Benedict RH, Cookfair D, Gavett R, Gunther M, Munschauer F, Garg N, et al. Validity of the minimal assessment of cognitive function in multiple sclerosis (MACFIMS). J Int Neuropsychol Soc (2006) 12:549-58. doi:10.1017/ S1355617706060723 data. NV, SC, DL, DC, KM, and SP were all involved in patient recruitment and assessment. JC conducted the statistical analyses, interpreted the data, and drafted the manuscript. All of the authors critically reviewed and approved the manuscript prior to its submission for publication.

\section{ACKNOWLEDGMENTS}

SP is funded by a fellowship from NHS Research Scotland.

\section{FUNDING}

This research did not receive any specific grant from funding agencies in the public, commercial, or not-for-profit sectors.

16. Langdon DW, Amato MP, Boringa J, Brochet B, Foley F, Fredrikson $\mathrm{S}$, et al. Recommendations for a brief international cognitive assessment for multiple sclerosis (BICAMS). Mult Scler (2012) 18:891-8. doi: $10.1177 / 1352458511431076$

17. Robbins TW, James M, Owen AM, Sahakian BJ, McInnes L, Rabbitt P. Cambridge neuropsychological test automated battery (CANTAB): a factor analytic study of a large sample of normal elderly volunteers. Dementia (1994) 5:266-81.

18. Robbins TW, James M, Owen AM, Sahakian BJ, Lawrence AD, McInnes L, et al. A study of performance on tests from the CANTAB battery sensitive to frontal lobe dysfunction in a large sample of normal volunteers: implications for theories of executive functioning and cognitive aging. Cambridge neuropsychological test automated battery. J Int Neuropsychol Soc (1998) 4:474-90.

19. Barnett JH, Blackwell AD, Sahakian BJ, Robbins TW. The paired associates learning (PAL) test: 30 years of CANTAB translational neuroscience from laboratory to bedside in dementia research. Curr Top Behav Neurosci (2016) 28:449-74. doi:10.1007/7854_2015_5001

20. Barnett JH, Robbins TW, Leeson VC, Sahakian BJ, Joyce EM, Blackwell AD. Assessing cognitive function in clinical trials of schizophrenia. Neurosci Biobehav Rev (2010) 34:1161-77. doi:10.1016/j.neubiorev.2010.01.012

21. Blackwell AD, Sahakian BJ, Vesey R, Semple JM, Robbins TW, Hodges JR. Detecting dementia: novel neuropsychological markers of preclinical Alzheimer's disease. Dement Geriatr Cogn Disord (2004) 17:42-8. doi:10.1159/ 000074081

22. Chamberlain SR, Robbins TW, Winder-Rhodes S, Müller U, Sahakian BJ, Blackwell AD, et al. Translational approaches to frontostriatal dysfunction in attention-deficit/hyperactivity disorder using a computerized neuropsychological battery. Biol Psychiatry (2011) 69:1192-203. doi:10.1016/j. biopsych.2010.08.019

23. Rock PL, Roiser JP, Riedel WJ, Blackwell AD. Cognitive impairment in depression: a systematic review and meta-analysis. Psychol Med (2014) 44:2029-40. doi:10.1017/S0033291713002535

24. Foong J, Rozewicz L, Quaghebeur G, Davie CA, Kartsounis LD, Thompson AJ, et al. Executive function in multiple sclerosis. The role of frontal lobe pathology. Brain (1997) 120:15-26. doi:10.1093/brain/120.1.15

25. Muhlert N, Atzori M, De Vita E, Thomas DL, Samson RS, Wheeler-Kingshott $\mathrm{CA}$, et al. Memory in multiple sclerosis is linked to glutamate concentration in grey matter regions. J Neurol Neurosurg Psychiatry (2014) 85:833-9. doi:10.1136/jnnp-2013-306662

26. Roque DT, Teixeira RAA, Zachi EC, Ventura DF. The use of the Cambridge neuropsychological test automated battery (CANTAB) in neuropsychological assessment: application in Brazilian research with control children and adults with neurological disorders. Psychol Neurosci (2011) 4:255-65. doi:10.3922/j. psns.2011.2.011

27. Sumowski JF. Cognitive reserve as a useful concept for early intervention research in multiple sclerosis. Front Neurol (2015) 6:176. doi:10.3389/ fneur.2015.00176 
28. Polman CH, Reingold SC, Banwell B, Clanet M, Cohen JA, Filippi M, et al. Diagnostic criteria for multiple sclerosis: 2010 revisions to the McDonald criteria. Ann Neurol (2011) 69:292-302. doi:10.1002/ana.22366

29. Kurtzke JF. Rating neurologic impairment in multiple sclerosis: an expanded disability status scale (EDSS). Neurology (1983) 33:1444-52. doi:10.1212/ WNL.33.11.1444

30. Sheikh JI, Yesavage JA. Geriatric depression scale (GDS): recent evidence and development of a shorter version. Clin Gerontologist (1986) 5:165-73. doi:10.1300/J018v05n01_09

31. Glanz BI, Healy BC, Rintell DJ, Jaffin SK, Bakshi R, Weiner HL. The association between cognitive impairment and quality of life in patients with early multiple sclerosis. J Neurol Sci (2010) 290:75-9. doi:10.1016/j.jns.2009.11.004

32. Matias-Guiu JA, Cortés-Martínez A, Valles-Salgado M, Oreja-Guevara C, Pytel V, Montero P, et al. Functional components of cognitive impairment in multiple sclerosis: a cross-sectional investigation. Front Neurol (2017) 8:643. doi:10.3389/fneur.2017.00643

33. McIntosh-Michaelis SA, Roberts MH, Wilkinson SM, Diamond ID, McLellan DL, Martin JP, et al. The prevalence of cognitive impairment in a community survey of multiple sclerosis. Br J Clin Psychol (1991) 30:333-48. doi:10.1111/ j.2044-8260.1991.tb00954.x

34. Achiron A, Chapman J, Magalashvili D, Dolev M, Lavie M, Bercovich E, et al. Modeling of cognitive impairment by disease duration in multiple sclerosis: a cross-sectional study. PLoS One (2013) 8:e71058. doi:10.1371/journal. pone. 0071058

35. Ruano L, Portaccio E, Goretti B, Niccolai C, Severo M, Patti F, et al. Age and disability drive cognitive impairment in multiple sclerosis across disease subtypes. Mult Scler (2017) 23:1258-67. doi:10.1177/1352458516674367

36. Johnen A, Landmeyer NC, Bürkner PC, Wiendl H, Meuth SG, Holling H. Distinct cognitive impairments in different disease courses of multiple sclerosis - a systematic review and meta-analysis. Neurosci Biobehav Rev (2017) 83:568-78. doi:10.1016/j.neubiorev.2017.09.005

37. Planche V, Gibelin M, Cregut D, Pereira B, Clavelou P. Cognitive impairment in a population-based study of patients with multiple sclerosis: differences between late relapsing-remitting, secondary progressive and primary progressive multiple sclerosis. Eur J Neurol (2016) 23:282-9. doi:10.1111/ ene. 12715

38. Compston A, Coles A. Multiple sclerosis. Lancet (2008) 372:1502-17. doi:10.1016/S0140-6736(08)61620-7

39. Luerding R, Gebel S, Gebel EM, Schwab-Malek S, Weissert R. Influence of formal education on cognitive reserve in patients with multiple sclerosis. Front Neurol (2016) 7:46. doi:10.3389/fneur.2016.00046

40. Lucchinetti C, Brück W, Parisi J, Scheithauer B, Rodriguez M, Lassmann H. Heterogeneity of multiple sclerosis lesions: implications for the pathogenesis of demyelination. Ann Neurol (2000) 47:707-17. doi:10.1002/ 1531-8249(200006)47:6<707::AID-ANA3>3.0.CO;2-Q

41. Weiner HL. The challenge of multiple sclerosis: how do we cure a chronic heterogeneous disease? Ann Neurol (2009) 65:239-48. doi:10.1002/ana.21640

42. Cotter J, Muhlert N, Talwar A, Granger K. Examining the effectiveness of acetylcholinesterase inhibitors and stimulant-based medications for cognitive dysfunction in multiple sclerosis: a systematic review and meta-analysis. Neurosci Biobehav Rev (2018) 86:99-107. doi:10.1016/j.neubiorev.2018. 01.006
43. Roy S, Benedict RH, Drake AS, Weinstock-Guttman B. Impact of pharmacotherapy on cognitive dysfunction in patients with multiple sclerosis. CNS Drugs (2016) 30:209-25. doi:10.1007/s40263-016-0319-6

44. Briken S, Gold SM, Patra S, Vettorazzi E, Harbs D, Tallner A, et al. Effects of exercise on fitness and cognition in progressive MS: a randomized, controlled pilot trial. Mult Scler (2014) 20:382-90. doi:10.1177/1352458513507358

45. das Nair R, Martin KJ, Lincoln NB. Memory rehabilitation for people with multiple sclerosis. Cochrane Database Syst Rev (2016) 3:CD008754. doi:10.1002/14651858.CD008754.pub3

46. Rosti-Otajärvi EM, Hämäläinen PI. Neuropsychological rehabilitation for multiple sclerosis. Cochrane Database Syst Rev (2014) 2:CD009131. doi:10.1002/14651858.CD009131.pub3

47. Sandroff BM, Johnson CL, Motl RW. Exercise training effects on memory and hippocampal viscoelasticity in multiple sclerosis: a novel application of magnetic resonance elastography. Neuroradiology (2017) 59:61-7. doi:10.1007/ s00234-016-1767-x

48. Sandroff BM, Motl RW, Scudder MR, DeLuca J. Systematic, evidence-based review of exercise, physical activity, and physical fitness effects on cognition in persons with multiple sclerosis. Neuropsychol Rev (2016) 26:271-94. doi:10.1007/s11065-016-9324-2

49. Collerton J, Collerton D, Arai Y, Barrass K, Eccles M, Jagger C, et al. A comparison of computerized and pencil-and-paper tasks in assessing cognitive function in community-dwelling older people in the Newcastle 85+ Pilot Study. J Am Geriatr Soc (2007) 55:1630-5. doi:10.1111/j.1532-5415.2007.01379.x

50. Cotter J, Granger K, Backx R, Hobbs M, Looi CY, Barnett J. Social cognitive dysfunction as a clinical marker: a systematic review of meta-analyses across 30 clinical conditions. Neurosci Biobehav Rev (2018) 84:92-9. doi:10.1016/j. neubiorev.2017.11.014

51. Cotter J, Muhlert N. White matter changes and social cognitive function in MS: when all is no longer in the eyes. Neurology (2017) 89:16-7. doi:10.1212/ WNL.0000000000004069

52. Krupp LB. Fatigue in multiple sclerosis: definition, pathophysiology and treatment. CNS Drugs (2003) 17:225-34. doi:10.2165/00023210-200317040-00002

53. Rule BG, Harvey HZ, Dobbs AR. Reliability of the geriatric depression scale for younger adults. Clin Gerontol (1990) 9:37-43. doi:10.1300/J018v09n02_05

54. FerraroFR,ChelminskiI.Preliminarynormativedata on thegeriatricdepression scale-shortform(GDS-SF)inayoung adultsample.J ClinPsychol(1996) 52:4437. doi:10.1002/(SICI)1097-4679(199607)52:4<443::AID-JCLP9>3.0.CO;2-Q

55. Weintraub D, Saboe K, Stern MB. Effect of age on geriatric depression scale performance in Parkinson's disease. Mov Disord (2007) 22:1331-5. doi:10.1002/mds.21369

Conflict of Interest Statement: JC, FC, and JB are employees of Cambridge Cognition Ltd. The remaining authors report no other conflict of interest.

Copyright (c) 2018 Cotter, Vithanage, Colville, Lyle, Cranley, Cormack, Barnett, Murray and Pal. This is an open-access article distributed under the terms of the Creative Commons Attribution License (CCBY). The use, distribution or reproduction in other forums is permitted, provided the original author(s) and the copyright owner are credited and that the original publication in this journal is cited, in accordance with accepted academic practice. No use, distribution or reproduction is permitted which does not comply with these terms. 